\title{
Sequence of the Bacillus subtilis genome region in the vicinity of the lev operon reveals two new extracytoplasmic function RNA polymerase sigma factors SigV and SigZ
}

\author{
Alexei Sorokin, ${ }^{1}$ Alexandre Bolotin, ${ }^{1}$ Bénédicte Purnelle, ${ }^{2}$ \\ Helmut Hilbert, ${ }^{3}$ Juergen Lauber, ${ }^{3}$ Andreas Düsterh ${ }^{\circ} \mathrm{ft}^{3}$ and \\ S. Dusko Ehrlich ${ }^{1}$
}

\footnotetext{
1 Laboratoire de Génétique Microbienne, Institut National de la Recherche Agronomique, Domaine de Vilvert, 78352 Jouy-enJosas cedex, France

2 Unité de Biochimie Physiologique, Universite Catholique de Louvain, Place Croix-du-sud 2/20, 1348 Louvain-la-Neuve, Belgium

3 QIAGEN GmbH, MaxVolmer-Straße 4, 40724 Hilden, Germany
}

\author{
Author for correspondence: Alexei Sorokin. Tel: +331346525 33. Fax: +33134652521.
} e-mail: sorokine@biotec.jouy.inra.fr
Keywords: Bacillus subtilis genome sequencing, extra cytoplasmic function $\sigma$-factors

Two regions with sizes 18900 and 25400 bp, which join previously known contigs containing levRDEFG, aadK and blt genes near $235^{\circ}$ of the Bacillus subtilis chromosome, were sequenced. Among others, two genes, which encode proteins homologous to RNA polymerase $\sigma$-factors, were identified within this region. The gene products designated SigV and SigZ, show the highest homology with $\sigma$-factors encoded by the gene carQ of Myxococcus xanthus and sigX (formerly orfX20) of B. subtilis, correspondingly. All $\sigma$-factors which show statistically significant homology to SigV and SigZ, belong to the ECF (extracytoplasmic functions) subfamily. SigV and Sigz do not have $\mathbf{N}$ terminal sequence which prevents such proteins from binding to DNA without RNA polymerase core enzyme.
An approach for understanding the functions of unknown genes, discovered by systematic genome sequencing, can be based on studies of complex regulons. The genes in such regulons, which we define as those for which expression depends on a pleiotropic regulator, are supposed to be related by their biological function. Assigning a gene to a regulon would therefore allow one to restrict the number of biochemical tests required to establish the gene function. The prominent candidates for such pleiotropic regulators in bacteria are the two-component signal transduction systems and RNA polymerase $\sigma$-factors. These regulators are responsible for induction of expression of different sets of genes highly specialized in driving the cell to one or another type of stationary phase differentiation. At least seven two-component systems (Msadek et al., 1993) and $11 \sigma$-factors (Haldenwang, 1995; Lonetto et al., 1994) were described for Bacillus subtilis, a bacteria with a well-developed ability for environmental adaptation. We present here the results of sequencing analysis of 18900 and $25400 \mathrm{bp}$ regions which join and extend

The GenBank accession numbers for the sequences reported in this paper are U93874, U93875 and U93876. two previously known contigs which include blt (SubtiList contig SL194-2, Moszer et al., 1996; Mizuno et al., 1996; Sorokin et al., 1996; Capuano et al., 1996), aadK (Ohmiya et al., 1989) and sacC (Parro et al., 1997) genes near $235^{\circ}$ on the $B$. subtilis chromosome (Bolotin et al., 1996). Special attention is brought to structural characterization of new $\sigma$-factor genes, which we designate $\operatorname{sig} V$ and $\operatorname{sig} Z$.

The 18900 and $25400 \mathrm{bp}$ areas, corresponding to physical coordinates 2715 to $2790 \mathrm{~kb}$ on the $B$. subtilis chromosome (Itaya, 1993) were amplified by Long Accurate PCR as described elsewhere (Bolotin et al., 1996). Sequencing was performed by cloning of this DNA, randomized by Sau3A, AluI or HaeIII restriction enzymes in M13mp18 or mp19 vector. Gap closure and final sequence verification was performed by direct sequencing of PCR products corresponding to gaps using the ABI PRISM dye-terminator sequencing kit (Perkin Elmer). The final sequence, determined on both strands, was analysed for putative genes as described by Sorokin et al. (1993). The main results of analysis are presented in Table 1 and Fig. 1. In $44300 \mathrm{bp}$ of the new sequence we detected 41 ORFs. For 29 of them homology was found with known proteins, from which 24 have 
Table 1. ORF features

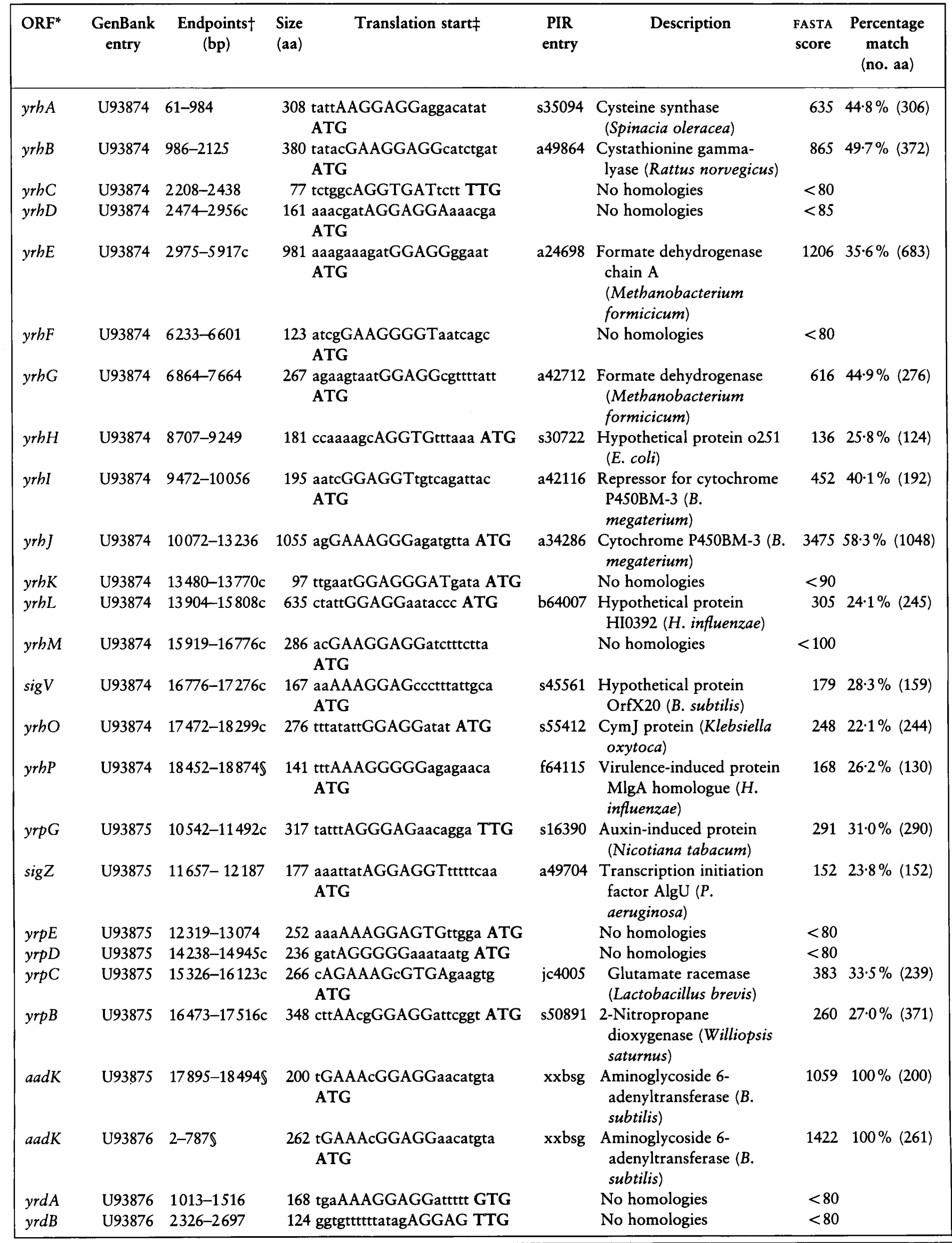


Table 1 (cont.)

\begin{tabular}{|c|c|c|c|c|c|c|c|}
\hline ORF $^{*}$ & $\begin{array}{c}\text { GenBank } \\
\text { entry }\end{array}$ & $\begin{array}{l}\text { Endpoints } \dagger \\
\quad \text { (bp) }\end{array}$ & Translation startł & $\begin{array}{c}\text { PIR } \\
\text { entry }\end{array}$ & Description & $\begin{array}{l}\text { FASTA } \\
\text { score }\end{array}$ & $\begin{array}{l}\text { Percentage } \\
\text { match } \\
\text { (no. aa) }\end{array}$ \\
\hline$y r d C$ & U93876 & $2926-3489$ & 188 tacgtAGGAGGgtatctt GTG & s28969 & $\begin{array}{l}N \text {-Carbamoylsarcosine } \\
\text { amidohydrolase } \\
\text { (Artbrobacter sp.) }\end{array}$ & 131 & $37.5 \%(72)$ \\
\hline$y r d D$ & U93876 & $3588-3737$ & 50 ctcagAGGAGGtgcatca ATG & & No homologies & $<60$ & \\
\hline$y r d E$ & U93876 & $4130-5362$ & 411 aaagatGGAGGtcgaatga ATG & b42606 & $\begin{array}{l}\text { Cytochrome P450CVIIB1 } \\
\text { (Saccharopolyspora } \\
\text { erythraea) }\end{array}$ & 881 & $41.8 \%(392)$ \\
\hline$y r d F$ & U93876 & $5634-5909$ & 92 taatGGAGGgcatagtttcta ATG & s01373 & $\begin{array}{l}\text { Ribonuclease inhibitor (B. } \\
\text { amyloliquefaciens) }\end{array}$ & 248 & $49 \cdot 4 \%(81)$ \\
\hline$y r d G$ & U93876 & $6243-6716$ & 158 tattGGGGGTtgtgaa ATG & s59993 & $\begin{array}{l}\text { Leucine-responsive } \\
\text { regulator }(S . \\
\text { typhimurium })\end{array}$ & 316 & $32.7 \%(150)$ \\
\hline$y r d H$ & U93876 & $6729-7493$ & 255 atgtAGGAGGTtgttgat TTG & $\mathrm{f} 64041$ & $\begin{array}{l}\text { Hypothetical protein } \\
\text { HI1738 (H. influenzae })\end{array}$ & 757 & $49.8 \%(235)$ \\
\hline$y r d I$ & U93876 & $7490-7822$ & 111 aagctGAGGTttccgt ATG & e64041 & $\begin{array}{l}\text { Hypothetical protein } \\
\text { HI1737 (H. influenzae) }\end{array}$ & 397 & $53.7 \%(108)$ \\
\hline$y r d J$ & U93876 & $7987-9309$ & $\begin{array}{c}441 \text { ttaatcGGAGGatatata ATG } \\
\text {. }\end{array}$ & $s 60180$ & $\begin{array}{l}\text { Branched-chain amino } \\
\text { acid carrier BrnQ } \\
\text { (Lactobacillus } \\
\text { delbrueckii) }\end{array}$ & 1029 & $41 \cdot 7 \%(427)$ \\
\hline$y r d K$ & U93876 & $9267-9584$ & 106 tattgcAGGAGGaat ATG & & No homologies & $<80$ & \\
\hline$y r d L$ & U93876 & $9742-10632 c$ & 297 caactatGGAGGactag ATG & b53305 & $\begin{array}{l}\mathrm{CO}_{2} \text { fixation transcription } \\
\text { activator CbbR } \\
\text { (Rhodospirillum rubrum) }\end{array}$ & 328 & $27 \cdot 1 \%(288)$ \\
\hline$y r d N$ & U93876 & 10966-11355 & 130 tagAAGGAGGggatttt ATG & & No homologies & $<80$ & \\
\hline$y r d O$ & U93876 & $11642-12577$ & 312 ggtAAGGAGGagtttttt ATG & d33830 & $\begin{array}{l}\text { Cation efflux system } \\
\text { membrane protein CzcD } \\
\text { (Alcaligenes eutrophus) }\end{array}$ & 497 & $44.3 \%(192)$ \\
\hline$y r d P$ & U93876 & $12665-13702$ & 346 aaattggcGGGGTGTtaat GTG & s29125 & $\begin{array}{l}\text { Dimethylaniline } \\
\text { monooxygenase (Homo } \\
\text { sapiens) }\end{array}$ & 127 & $26.8 \%(157)$ \\
\hline$y r d Q$ & U93876 & $13825-14691 \mathrm{c}$ & $\begin{array}{l}289 \text { ttaatGAAGGGGGgatcttc } \\
\text { ATG }\end{array}$ & b53305 & $\begin{array}{l}\mathrm{CO}_{2} \text { fixation transcription } \\
\text { activator CbbR } \\
\text { (Rhodospirillum rubrum) }\end{array}$ & 322 & $28.7 \%(247)$ \\
\hline$y r d R$ & U93876 & $14817-15782$ & 322 aAAAGGAGGggaattca ATG & e64182 & $\begin{array}{l}\text { Cysteine synthase CysZ } \\
\text { homologue }(H . \\
\text { influenzae })\end{array}$ & 98 & $19 \cdot 3 \%(233)$ \\
\hline$y r k A$ & U93876 & $16206-17510$ & 435 actaggtAAGGcaaatca TTG & h64142 & $\begin{array}{l}\text { Hypothetical protein } \\
\text { HI0107 (H. influenzae) }\end{array}$ & 424 & $24 \cdot 0 \%(420)$ \\
\hline
\end{tabular}

"Nomenclature for the putative ORFs is described by Sorokin et al. (1996).

†n the corresponding GenBank entry.

¥Putative start codons are indicated by bold letters and the nucleotides complementary to $16 \mathrm{~S}$ RNA are indicated by upper-case letters. \Partial sequence in this GenBank entry. The complete size of this ORF is $855 \mathrm{bp}$.

their biological function or protein activity identified either experimentally or by similarity to other known proteins. Five ORFs encoded homologues of hypothetical proteins and for 12 no homology was found. There is no obvious 'functional orientation' of this area of the B. subtilis genome. However, our attention was drawn to two ORFs, designated sig $V$ and sig $Z$, encoding proteins which have similarity with RNA polymerase $\sigma$-factors. Using amino acid sequences of different $\sigma$-factors of this subfamily, revealed by homology to SigV and SigZ, we screened SWISS-PROT and Protein Information Resource (PIR) databases to detect all homologous proteins. Nineteen proteins were detected, having in most cases $22-30 \%$ identical amino acids over the whole length with a FASTA score between 100 and 200 (not shown). These parameters were used to assign 

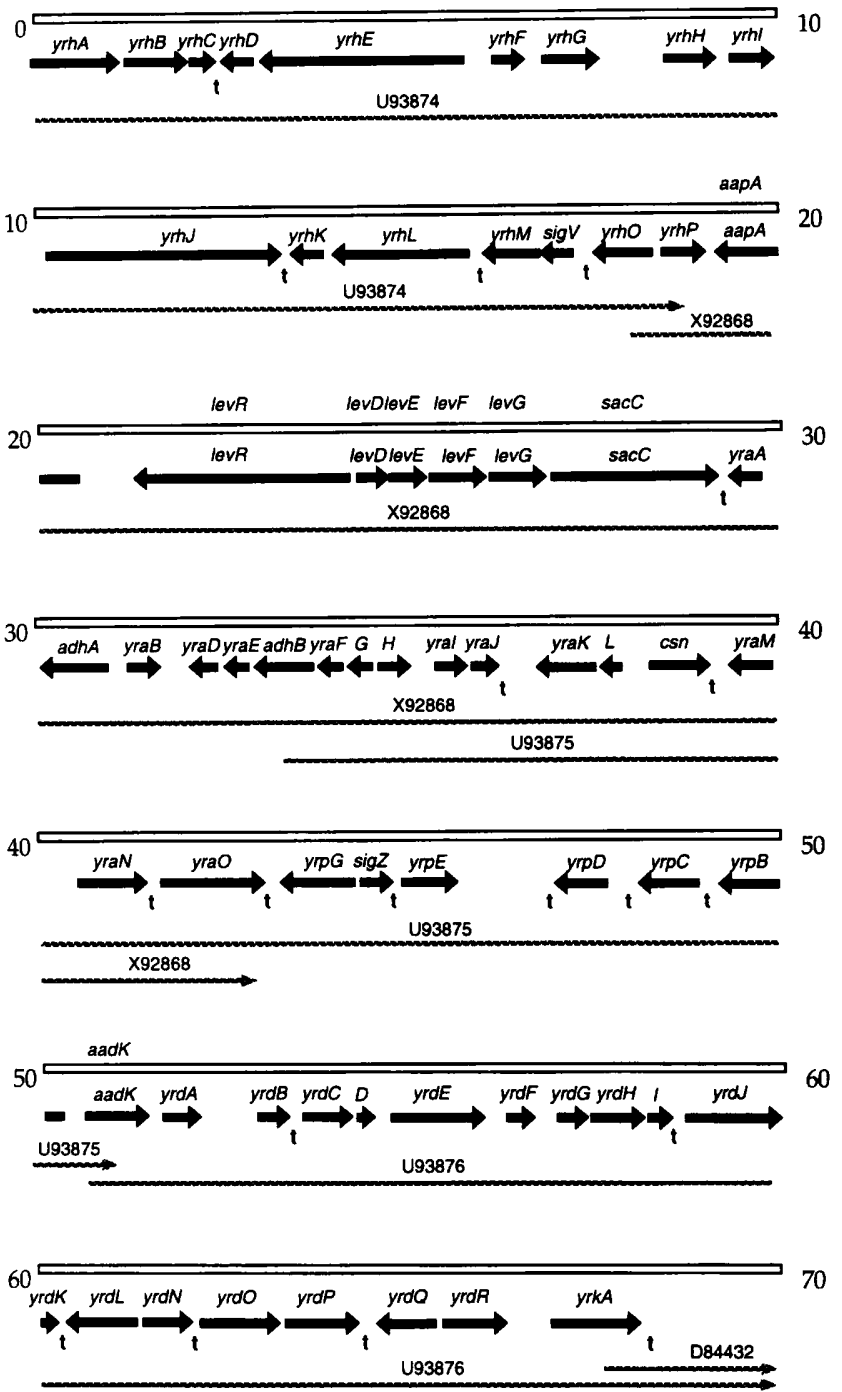

Fig. 1. ORF map of the area sequenced. Overlapping GenBank entries are shown by hatched arrows. Details of the ORFs are presented in Table 1. Known genes are indicated above the scale bar. Sequences with accession numbers U93874, U93875 and $U 93876$ were determined in the course of the present work. ORF designations are in accordance with the $B$. subtilis genome sequencing project (Moszer et al., 1996).

a protein to this subfamily. Several pairs of proteins have more than $45 \%$ identical amino acids. These are Escherichia coli FecI and Pseudomonas putida PupI (45.6\% over $158 \mathrm{aa})$, Pseudomonas aeruginosa PvdS and Pseudomonas fluorescens $\mathrm{PbrA}(89 \cdot 8 \%$ over 177 aa). $P$. aeruginosa AlgU shares $62-66 \%$ of identical amino acids with three $\sigma$-factors, called RpoE, from $E$. coli, Salmonella typhimurium and Haemophilus influenzae. The last three have $73-76 \%$ identity. The encoded regulators appear to belong to a recently recognized subfamily of $\sigma$-factors involved in the regulation of extracytoplasmic functions (ECF, Lonetto et al., 1994). Three other such genes in $B$. subtilis were identified by systematic sequencing of the genome: $\operatorname{sig} X$ (Sorokin et al., 1993), sigY (Yoshida et al., 1996) and $y b b L$

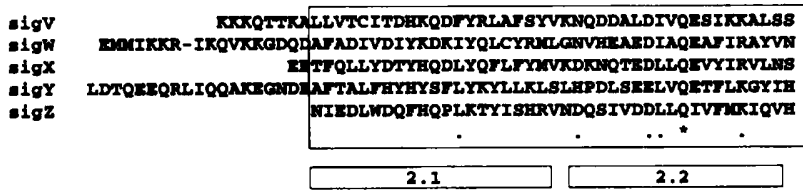

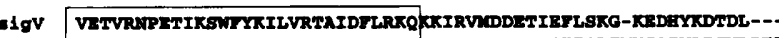

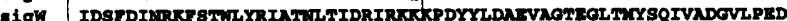
1 X

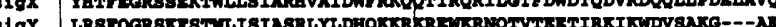
1 I

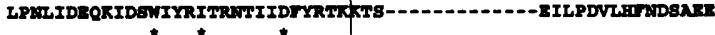

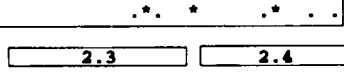

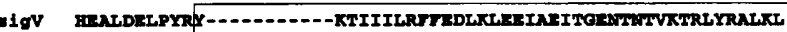

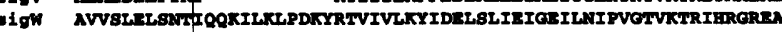
IGX HEWVRIISCALDOCTIDQ----RAVIILRTIQGYSIQITAXALRFSESKVKTTQHROLKV

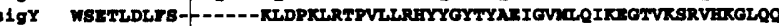
ligZ ENTTKCATVCIRSTIKRLPEKYREALELTDFQGLSQKCLSEKLOISYSGAKSRVQRGRG

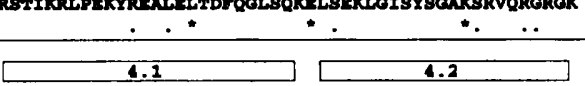

-igV MRIQLTKads

-1gW Lew0is--DL

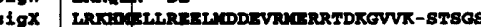

igY IRKator

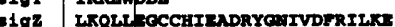

Fig. 2. Multiple alignment of known ECF $\sigma$-factors from $B$. subtilis. The highly conserved regions 2 and 4 are boxed. See text for the nomenclature of $\sigma$-factors and the relevant references.

(proposed to be designated sigW) (H. Liu and others, accession no. D84214)

Multiple alignment of these five $\sigma$-factors (Fig. 2) reveals that seven amino acid residues are conserved in all of them. It also indicates that $\sigma^{\mathrm{Z}}$ and $\sigma^{\mathrm{v}}$, as well as $\sigma^{\mathrm{X}}$, do not have the $\mathrm{N}$-terminal sequence which prevents these proteins from binding to DNA without RNA polymerase core enzyme (Dombroski et al., 1992, 1993). It is worth mentioning also that three ECF $\sigma$-factor genes in $B$. subtilis have in their vicinity a gene which can be cotranscribed or divergently transcribed, thus forming an operon or a divergon with the corresponding $\sigma$-factor gene. These are: $y p u N$ for $\operatorname{sig} X, y r b M$ for $\operatorname{sig} V$ and $y r p G$ for sigZ. It was demonstrated in several cases that ECF $\sigma$-factors are negatively regulated by the products of such genes in their vicinity (van Hove et al., 1990; Koster et al., 1994; Huang et al., 1997). This may therefore be a common feature for these ECF $\sigma$-factors in B. subtilis.

\section{ACKNOWLEDGEMENTS}

This work was supported, in part, by grants from GREG (décision 21) and EEC (BIO2-CT93-0272 and BIO2-CT942011).

\section{REFERENCES}

Bolotin, A., Sorokin, A. \& Ehrlich, S. D. (1996). Mapping of the $150 \mathrm{~kb}$ spolllC-pheA region of the Bacillus subtilis chromosome by using Long Accurate PCR and three yeast artificial chromosomes. Microbiology 142, 3017-3020.

Capuano, V., Galleron, N., Pujic, P., Sorokin, A. \& Ehrlich, S. D. (1996). Organization of the Bacillus subtilis 168 chromosome between $k d g$ and the attachment site of the $S P \beta$ prophage: use of Long Accurate PCR and yeast artificial chromosomes for sequencing. Microbiology 142, 3005-3015. 
Dombroski, A. J., Walter, W. A., Record, M. T., Siegele, D. A. \& Gross, C. A. (1992). Polypeptides containing highly conserved regions of transcription initiation factor sigma 70 exhibit specificity of binding to promoter DNA. Cell 70, 501-512.

Dombroski, A. J., Walter, W. A. \& Gross, C. A. (1993). Aminoterminal amino acids modulate sigma-factor DNA-binding activity. Genes Dev 7, 2446-2455.

Haldenwang, W. G. (1995). The sigma factors of Bacillus subtilis. Microbiol Rev 59, 1-30.

van Hove, B., Staudenmaier, H. \& Braun, V. (1990). Novel twocomponent transmembrane transcription control: regulation of iron dicitrate transport in Escherichia coli K-12. J Bacteriol 172, 6749-6758.

Huang, X., Decatur, A., Sorokin, A. \& Helmann, J. D. (1997). The Bacillus subtilis $\sigma^{\mathrm{x}}$ protein is an extracytoplasmic function $\sigma$ factor contributing to survival at high temperature. $J$ Bacteriol 179, $2915-2921$.

Itaya, M. (1993). Physical map of the Bacillus subtilis 168 chromosome. In Bacillus subtilis and Other Gram-positive Bacteria, pp. 463-472. Edited by A. L. Sonenshein, J. A. Hoch \& R. Losick. Washington, DC: American Society for Microbiology.

Koster, M., van Klompenburg, W., Bitter, W., Leong, J. \& Weisbeek, P. (1994). Role of the outer membrane ferric siderophore receptor PupB in signal transduction across the bacterial cell envelope. $E M B O J$ 13, 2805-2813.

Lonetto, M. A., Brown, K. L., Rudd, K. E. \& Buttner, M. J. (1994). Analysis of the Streptomyces coelicolor sigE gene reveals the existence of a subfamily of eubacterial RNA polymerase $\sigma$ factors involved in the regulation of extracytoplasmic functions. Proc Natl Acad Sci USA 91, 7573-7577.

Mizuno, M., Masuda, S., Takemaru, K., Hosono, S., Sato, T., Takeuchi, M. \& Kobayashi, Y. (1996). Systematic sequencing of the $283 \mathrm{~kb} 210^{\circ}-232^{\circ}$ region of the Bacillus subtilis genome con- taining the skin element and many sporulation genes. Microbiology 142, 3103-3111.

Moszer, I., Kunst, F. \& Danchin, A. (1996). The European Bacillus subtilis genome sequencing project: current status and accessibility of the data from a new World Wide Web site. Microbiology 142, 2987-2991.

Msadek, T., Kunst, F. \& Rapoport, G. (1993). Two-component regulatory systems. In Bacillus subtilis and other Gram-positive Bacteria, pp. 729-746. Edited by A. L. Sonenshein, J. A. Hoch \& R. Losick. Washington, DC: American Society for Microbiology.

Ohmiya, K., Tanaka, T., Noguchi, N., O'Hara, K. \& Kono, M. (1989). Nucleotide sequence of the chromosomal gene coding for the aminoglycoside 6-adenyltransferase from Bacillus subtilis Marburg 168. Gene 78, 377-378.

Parro, V., San Román, M., Galindo, I., Purnelle, B., Bolotin, A., Sorokin, A. \& Mellado, R. P. (1997). A 23911 bp region of the Bacillus subtilis genome comprising genes located upstream and downstream of the lev operon. Microbiology 143, 1321-1326.

Sorokin, A., Zumstein, E., Azevedo, V., Ehrlich, S. D. \& Serror, P. (1993). The organization of the Bacillus subtilis 168 chromosome region between the spoVA and serA genetic loci. Mol Microbiol 10, 385-395.

Sorokin, A., Azevedo, V., Zumstein, E., Galleron, N., Ehrlich, S. D. \& Serror, P. (1996). Sequence analysis of the Bacillus subtilis chromosome region between the ser $A$ and $k d g$ loci cloned in a yeast artificial chromosome. Microbiology 142, 2005-2016.

Yoshida, K., Shindo, K., Sano, H., Seki, S., Fujimura, M., Yanai, N., Miwa, Y. \& Fujita, Y. (1996). Sequencing of a $65 \mathrm{~kb}$ region of the Bacillus subtilis genome containing the lic and cel loci, and creation of a $177 \mathrm{~kb}$ contig covering the gnt-sacXY region. Microbiology 142, 3113-3123.

Received 24 March 1997; revised 29 May 1997; accepted 2 June 1997. 